\title{
Shedding by ADAM10 and ADAM17 is associated with progression of adult T-cell leukemia/lymphoma
}

\author{
Shigeki Takemoto ${ }^{1,2 *}$, Tomohiro Kozako ${ }^{3}$ and Ratiorn Pornkuna ${ }^{1,4}$ \\ ${ }^{1}$ Department of International Cooperation, Graduate School of Medical Sciences, Kumamoto University, Japan \\ ${ }^{2}$ Clinical Laboratory, National Hospital Organization Kumamoto Medical Center, Japan \\ ${ }^{3}$ Department of Biochemistry, Faculty of Pharmaceutical Sciences, Fukuoka University, Japan \\ ${ }^{4}$ Nursing Department, Khon Kaen Regional Hospital, Thailand
}

\begin{abstract}
Adult T-cell leukemia/lymphoma (ATL) is a retrovirus-associated mature T-cell leukemia/lymphoma. It is speculated that ATL is an age-related disease and some changes are involved in malignant transformation and monoclonal expansion of the HTLV-1-infected cells. We previously reported that HTLV-1-infected cells and ATL cells exhibit CD30 and soluble CD30 (sCD30) is elevated in the sera of patients with ATL. Recently, we also evaluated the levels of sCD30 in ATL patients underwent chemotherapy and allogeneic hematopoietic stem cell transplantation (HSCT) to predict prognosis of ATL patients under 2 different clinical settings; before initiation therapy and before HSCT. Our results suggest that sCD30 may be a useful biomarker in HSCT therapy, because a high sCD30 level before HSCT was implicated in early death after HSCT. In addition, we report that sCD30 elevation was followed by acute crisis from chronic type of ATL. Previously, high levels of soluble proteins including cytokine receptor and membrane-binding protein were observed in patients with ATL. A disintegrin and metalloproteinase (ADAM)10 and ADAM17 worked as sheddases of CD30 as well as the other proteins. ADAM10/17 also cleaved collagen and elastin which are structural proteins of tissues and may cause the tissue injury of important organs. It seems that ADAM10/17 plays a role as oncoproteins for tumorigensis in ATL.
\end{abstract}

Adult T-cell leukemia/lymphoma (ATL) is a retrovirus-associated mature T-cell leukemia/lymphoma [1-4]. A mean latency period of more than 50 years is required for only $2-5 \%$ of human T-cell leukemia virus type 1 (HTLV-1) carriers to develop ATL [5,6]. It is speculated that ATL is an age-related disease and some changes are involved in malignant transformation and monoclonal expansion of the HTLV-1-infected cells [7]. We previously reported that HTLV-1infected cells and ATL cells exhibit CD30 and soluble CD30 (sCD30) is elevated in the sera of patients with ATL [8]. CD30 (also known as Ki$1, \mathrm{Ber}-\mathrm{H} 2$ and TNFRSF8) is a $120 \mathrm{kDa}$ type I cell surface glycoprotein and a member of the tumor necrosis factor receptor family. CD30 is physically expressed on activated $\mathrm{T}$ cells including $\mathrm{CD} 45 \mathrm{RO}+\mathrm{T}$ cells, $\mathrm{B}$ cells, NK cells and monocytes. Pathologically, CD30 expression is observed on viral infected cells and tumor cells such as B cell lymphoma, $\mathrm{T}$ cell lymphoma, acute myeloid leukemia, and embryonal carcinoma $[9,10]$. CD30+ cells release soluble CD30 (sCD30) in vitro and in vivo, detected at low levels in the sera of healthy donors [11]. Levels of sCD30 have been proposed to be a prognostic factor for an unfavorable outcome in lymphoid malignancies such as Hodgkin's lymphoma, and T-cell lymphomas [12-14]. Recently, we also evaluated the levels of sCD30 in ATL patients underwent chemotherapy and allogeneic hematopoietic stem cell transplantation (HSCT) to predict prognosis of ATL patients under 2 different clinical settings; before initiation therapy and before HSCT [15]. Levels of sCD30 were significant predictors of Overall Survival (OS) both before the initial therapy and before HSCT. Especially, our results suggest that sCD30 may be a useful biomarker in HSCT therapy, because a high sCD30 level before HSCT was implicated in early death after HSCT. In most of them, patients died of diffuse pulmonary infiltrates and/or interstitial pneumonia within 76 days. This is reason why ATL patients with sCD30 level $\geq 170 \mathrm{U} / \mathrm{ml}$ may not be a suitable transplantation therapy.
Hopefully, the use of this marker will help to reduce the early deaths and transplantation-related mortality of HSCT.

In addition, we reported that $\mathrm{SCD} 30$ elevation was followed by acute crisis from chronic type of ATL [16]. The lungs are the preferential site for HTLV-1-infected cells, and this peculiar tropism is responsible for the high incidence of pulmonary involvement [17-20]. A patient who progressed from indolent type to acute type of ATL showed lung invasion following elevation of the serum sCD30 levels. Furthermore, the level of sCD30 surged according to the formation of pulmonary lesions at relapse as well as at acute crisis of disease In the lung, Tax, trans-activator of HTLV-1 genome and cellular genes, is preferentially expressed in HTLV-1-infected cells [21] and the CD30 and CD30 ligand interaction plays an important role for inflammation [22,23]. Therefore, a sustained high level of sCD30 may be associated with Tax expression and pulmonary involvement of ATL.

Previously, high levels of soluble proteins including cytokine receptor and membrane-binding protein were observed in patients with ATL (Table 1). Soluble interleukin-6 receptor (sIL-6R) was shown

Correspondence to: Shigeki Takemoto, M.D., Ph.D, Chief of Clinical laboratory, National Hospital Organization Kumamoto Medical Center, 1-5 Ninomaru, Kumamoto 860-0008, Japan, Tel: +81-96-353-6501; Fax: +81-96-325-2519; E-mail: takemots@kumamed.jp

Key words: a disintegrin and metalloproteinase (ADAM)10, ADAM17, adult T-cell leukemia/lymphoma (ATL), human T-cell leukemia virus type 1 (HTLV-1), soluble CD30 (sCD30)

Received: January 18, 2015; Accepted: February 05, 2015; Published: February 05,2015 
Table 1. High levels of soluble proteins cleaved by ADAM10/17 in ATL patients.

\begin{tabular}{|l|c|c|}
\hline & ADAM10 & ADAM17 \\
\hline \multirow{3}{*}{ Shedding proteins on ATL cells } & CD30 [8,15] & CD30 [8,15] \\
\cline { 2 - 3 } & *Fas ligand (FasL) [28] & IL-6 receptor (IL-6R) [24] \\
\cline { 2 - 3 } & CD44 [27,32] & CD44 [27,32] \\
\hline
\end{tabular}

*This report was demonstrated in HTLV-1 carriers

ECM

(extracellular matrix)

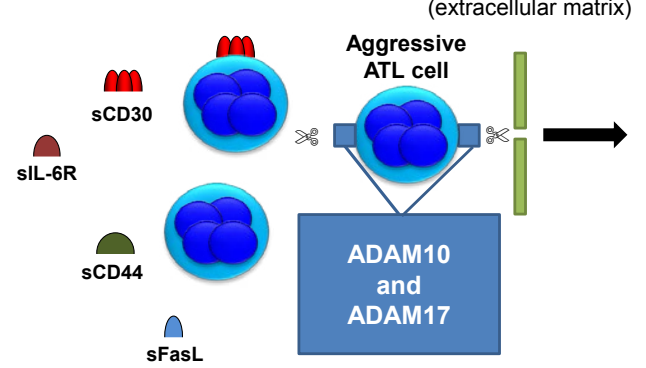

ADAM10 and ADAM17 can degrade ECM and may cause tissue injury

Figure 1. Aggressive phenotype of ATL cells.

ADAM10 and 17 cleave membrane-bound proteins, ligands and receptors, and fibrous proteins, which are involved in the tumorigenesis, development, and metastasis of tumors.

to circulate at elevated levels in HTLV-1-infected patients and to be associated activation of STAT3 signaling [24,25]. CD44 is a broadly distributed cell surface glycoprotein and has been identified as a tumor-promoting molecule that is implicated in cancer cell growth, invasion, and metastasis [26]. In vivo, plasma levels of soluble CD44 (sCD44) were significantly associated with the performance status, total number of involved lesions, and lactic dehydrogenase [27]. As mentioned above, HTLV-1 carriers are known to develop pulmonary complications characterized by T-lymphocytic alveolitis. Sakamoto $\mathrm{N}$ et al. measured soluble Fas (sFas) and sFas ligand ( $\mathrm{sFasL}$ ) in serum and bronchoalveolar lavage fluid of 16 seropositive asymptomatic HTLV-1 carriers and 32 healthy subjects, and the levels of sFasL were significantly higher in asymptomatic carriers than the control [28].

Accordingly, serum levels of sCD30 may be a marker of matrix matalloproteinases activation on ATL cells (Figure 1). A Disintegrin and metalloproteinase (ADAM)10 and ADAM17 work as sheddases of CD30 as well as the other proteins (sFasL, sCD44, and sIL-6R) as shown in Table 1 [29-32]. ADAM10/17 also cleaves collagen and elastin which are structural proteins of tissues and may cause the tissue injury of important organs. It seems that ADAM10/17 play a role as oncoproteins for tumorigensis in ATL.

\section{References}

1. Takatsuki K (2005) Discovery of adult T-cell leukemia. Retrovirology 2: 16. [Crossref]

2. Uchiyama T, Yodoi J, Sagawa K, Takatsuki K, Uchino H (1977) Adult T-cell leukemia: clinical and hematologic features of 16 cases. Blood 50: 481-492. [Crossref]

3. Poiesz BJ, Ruscetti FW, Gazdar AF, Bunn PA, Minna JD, et al. (1980) Detection and isolation of type $\mathrm{C}$ retrovirus particles from fresh and cultured lymphocytes of a patient with cutaneous T-cell lymphoma. Proc Natl Acad Sci U S A 77: 7415-7419. [Crossref]

4. Seiki M, Hattori S, Hirayama Y, Yoshida M (1983) Human adult T-cell leukemia virus: complete nucleotide sequence of the provirus genome integrated in leukemia cell DNA. Proc Natl Acad Sci U S A 80: 3618-3622. [Crossref]

5. Yamaguchi K (1994) Human T-lymphotropic virus type I in Japan. Lancet 343: 213 216. [Crossref]

6. Franchini G (1995) Molecular mechanisms of human T-cell leukemia/lymphotropic virus type I infection. Blood 86: 3619-3639. [Crossref]

7. Pornkuna R, Takemoto S (2014) A lack of cellular senescence, formation of microenvironment, and role of soluble CD30 in development of adult T-cell leukemia/ lymphoma. J Hematol Thrombo Dis 2: doi.org/10.4172/2329-8790. 1000151.
8. Nishioka C, Takemoto S, Kataoka S, Yamanaka S, Moriki T, et al. (2005) Serum level of soluble CD30 correlates with the aggressiveness of adult T-cell leukemia/lymphoma. Cancer Sci 96: 810-815. [Crossref]

9. Horie R, Watanabe T (1998) CD30: expression and function in health and disease Semin Immunol 10: 457-470. [Crossref]

10. Younes A, Carbone A (1999) CD30/CD30 ligand and CD40/CD40 ligand in malignant lymphoid disorders. Int J Biol Markers 14: 135-143. [Crossref]

11. Krampera M, Vinante F, Tavecchia L, Morosato L, Chilosi M, et al. (1999) Progressive polarization towards a $\mathrm{T}$ helper/cytotoxic type- 1 cytokine pattern during age-dependent maturation of the immune response inversely correlates with CD30 cell expression and serum concentration. Clin Exp Immunol 117: 291-297. [Crossref]

12. Nadali G, Tavecchia L, Zanolin E, Bonfante V, Viviani S, et al. (1998) Serum level of the soluble form of the CD30 molecule identifies patients with Hodgkin's disease at high risk of unfavorable outcome. Blood 91: 3011-3016. [Crossref]

13. Zinzani PL, Pileri S, Bendandi M, Buzzi M, Sabattini E, et al. (1998) Clinical implications of serum levels of soluble CD30 in 70 adult anaplastic large-cell lymphoma patients. J Clin Oncol 16: 1532-1537. [Crossref]

14. Kadin ME, Pavlov IY, Delgado JC, Vonderheid EC (2012) High soluble CD30, CD25, and IL-6 may identify patients with worse survival in CD30+ cutaneous lymphomas and early mycosis fungoides. J Invest Dermatol 132: 703-710. [Crossref]

15. Pornkuna R, Takemoto S, Hidaka M, Kawano F, Haga Y (2014) Clinical value of serum soluble CD30 levels in adult T-cell leukemia/lymphoma. J Hematol Thrombo Dis 2 167.

16. Takemoto S, Morimatsu Y, Pornkuna R, Murayama T, Kawano F (2015) CD30+ cells in lung of indolent type adult T-cell leukemia/lymphoma and elevated serum levels of soluble CD30 associated with acute crisis and relapse of disease. J Leuk (in press).

17. Sugimoto M, Mita S, Tokunaga M, Yamaguchi K, Cho I, et al. (1993) Pulmonary involvement in human T-cell lymphotropic virus type-I uveitis: T-lymphocytosis and high proviral DNA load in bronchoalveolar lavage fluid. Eur Respir J 6: 938-943. [Crossref]

18. Mori S, Mizoguchi A, Kawabata M, Fukunaga H, Usuku K, et al. (2005) Bronchoalveolar lymphocytosis correlates with human T lymphotropic virus type I (HTLV-I) proviral DNA load in HTLV-I carriers. Thorax 60: 138-143. [Crossref]

19. Okada F, Ando Y, Yoshitake S, Yotsumoto S, Matsumoto S, et al. (2006) Pulmonary CT findings in 320 carriers of human T-lymphotropic virus type 1. Radiology 240 : 559-564. [Crossref]

20. Yoshioka R, Yamaguchi K, Yoshinaga T, Takatsuki K (1985) Pulmonary complications in patients with adult T-cell leukemia. Cancer 55: 2491-2494. [Crossref]

21. Nakayama Y, Yamazato Y, Tamayose M, Atsumi E, Yara S, et al. (2013) Increased expression of HBZ and Foxp3 mRNA in bronchoalveolar lavage cells taken from human T-lymphotropic virus type 1-associated lung disorder patients. Intern Med 52: 2599-2609. [Crossref]

22. Nam SY, Kim YH, Do JS, Choi YH, Seo HJ, et al. (2008) CD30 supports lung inflammation. Int Immunol 20: 177-184. [Crossref]

23. Tang C, Yamada H, Shibata K, Muta H, Wajjwalku W, et al. (2008) A novel role of $\mathrm{CD} 30 \mathrm{~L} / \mathrm{CD} 30$ signaling by T-T cell interaction in Th1 response against mycobacterial infection. J Immunol 181: 6316-6327. [Crossref]

24. Horiuchi S, Yamamoto N, Dewan MZ, Takahashi Y, Yamashita A, et al. (2006) Human T-cell leukemia virus type-I Tax induces expression of interleukin-6 receptor (IL-6R): Shedding of soluble IL-6R and activation of STAT3 signaling. Int J Cancer 119: 823830. [Crossref]

25. Takemoto S, Mulloy JC, Cereseto A, Migone TS, Patel BK, et al. (1997) Proliferation of adult $\mathrm{T}$ cell leukemia/lymphoma cells is associated with the constitutive activation of JAK/STAT proteins. Proc Natl Acad Sci U S A 94: 13897-13902. [Crossref]

26. Zhang J, Yamada O, Kida S, Matsushita Y, Yamaoka S, et al. (2011) Identification of CD44 as a downstream target of noncanonical NF- $\kappa B$ pathway activated by human T-cell leukemia virus type 1-encoded Tax protein. Virology 413: 244-252. [Crossref]

27. Chagan-Yasutan H, Tsukasaki K, Takahashi Y, Oguma S, Harigae H, et al. (2011) Involvement of osteopontin and its signaling molecule CD44 in clinicopathological features of adult T cell leukemia. Leuk Res 35: 1484-1490. [Crossref]

28. Sakamoto N, Mukae H, Fujii T, Kakugawa T, Kaida H, et al. (2004) Soluble form of Fas and Fas ligand in serum and bronchoalveolar lavage fluid of individuals infected with human T-lymphotropic virus type 1. Respir Med 98: 213-219. [Crossref] 
29. Hansen HP, Dietrich S, Kisseleva T, Mokros T, Mentlein R, et al. (2000) CD30 shedding from Karpas 299 lymphoma cells is mediated by TNF-alpha-converting enzyme. $J$ Immunol 165: 6703-6709. [Crossref]

30. Vahdat AM, Reiners KS, Simhadri VL, Eichenauer DA, Böll B, et al. (2010) TNFalpha-converting enzyme (TACE/ADAM17)-dependent loss of CD30 induced by proteasome inhibition through reactive oxygen species. Leukemia 24: 51-57. [Crossref]
31. Eichenauer DA, Simhadri VL, von Strandmann EP, Ludwig A, Matthews V, et al. (2007) ADAM10 inhibition of human CD30 shedding increases specificity of targeted immunotherapy in vitro. Cancer Res 67: 332-338. [Crossref]

32. Nagao O, Murakami D, Hartmann D, De Strooper B, Saftig P, et al. (2004) Cellmatrix interaction via CD44 is independently regulated by different metalloproteinases activated in response to extracellular $\mathrm{Ca}^{2+}$ influx and PKC activation. $J$ Cell Biol 165 : 893-902. [Crossref]

Copyright: (C2015 Shigeki Takemoto. This is an open-access article distributed under the terms of the Creative Commons Attribution License, which permits unrestricted use, distribution, and reproduction in any medium, provided the original author and source are credited. 